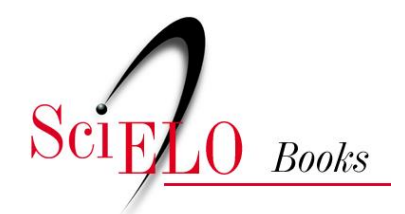

\author{
Vivendo na morte \\ a História dos Vampiros e seu lugar na cultura popular \\ Iliane Tecchio
}

TECCHIO, I. Vivendo na morte: a História dos Vampiros e seu lugar na cultura popular. In MAGALHÃES, ACM., et al., orgs. O demoníaco na literatura [online]. Campina Grande: EDUEPB, 2012. pp. 225-237. ISBN 978-85-7879-188-9. Available from SciELO Books

<http://books.scielo.org>.

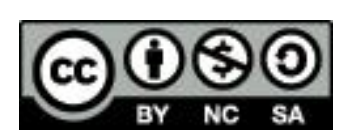

All the contents of this work, except where otherwise noted, is licensed under a Creative Commons Attribution-Non Commercial-ShareAlike 3.0 Unported.

Todo o conteúdo deste trabalho, exceto quando houver ressalva, é publicado sob a licença Creative Commons Atribuição Uso Não Comercial - Partilha nos Mesmos Termos 3.0 Não adaptada.

Todo el contenido de esta obra, excepto donde se indique lo contrario, está bajo licencia de la licencia Creative Commons Reconocimento-NoComercial-CompartirIgual 3.0 Unported. 


\section{Vivendo na morte: a História dos Vampiros e seu lugar na cultura popular}

Iliane Tecchio ${ }^{2}$

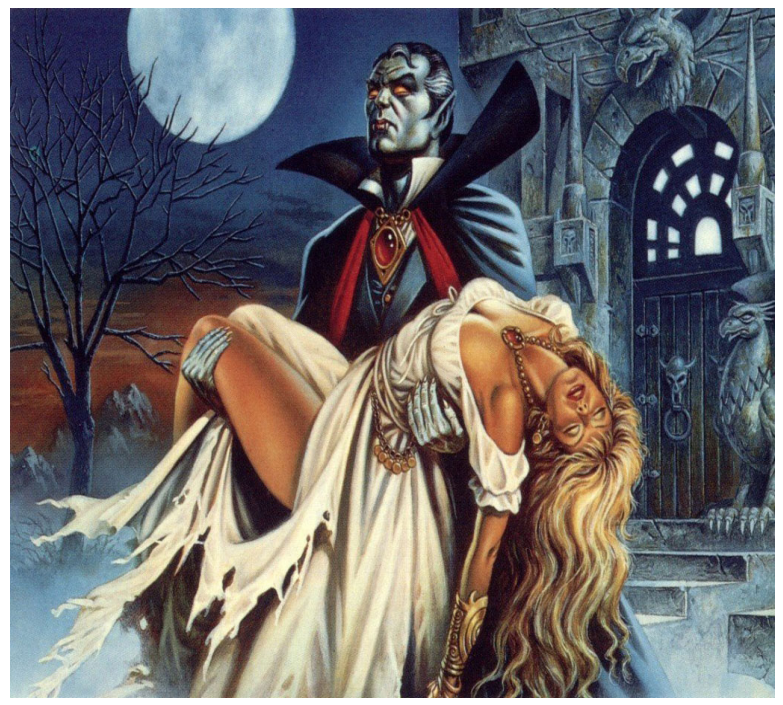

O vampiro é um ser lendário que tem sido temido por pessoas ao redor do mundo por muitos e muitos séculos. Apesar da grande diferença geográfica e temporal de onde surgiram as histórias sobre vampiros, o folclore que o abarca é surpreendentemente uniforme especialmente em relação aos poderes e as suas limitações do vampiro. De acordo com Melton (2003, p. XXXVII) em cada cultura o vampiro adquiriu características distintas que precisam ser levadas em consideração de acordo com seu contexto ambiental. A maioria das descrições sobre ataques

2 Doutoranda em Estudos da Tradução - UFSC- SC, professora de Língua Inglesa na rede Municipal de Educação do município de São José - SC. Email: iliane.tecchio@gmail.com 
destes temidos seres tem origem, principalmente, na Grécia, na China, na Índia, no Leste Europeu e "civilizações como a dos sumerianos, dos babilônios, dos indianos e os povos hebreus, maias e astecas conviveram como o fenômeno do Vampirismo." (TORRIGO, 2009, p. 10).

O vampiro é normalmente considerado como sendo aquele que existe no estado de "morto vivo", literalmente um corpo reanimado. Algumas tradições descrevem o vampiro como sendo um corpo habitado por um ser maligno, outros, como um corpo possuído por uma feitiçaria [uma situação dentro dos domínios da magia negra] e ainda outros que descrevem o vampiro como um corpo possuído pela alma que ele tinha em vida. Para Bourre (1986, p. 04) a Europa Central foi, durante muito tempo, o feudo "destes senhores da noite", e que as antigas religiões caracterizavam como diabos ou demônios. "Para um vasto público," afirma Lecouteux (2005, p. 10) “o vampiro é um sugador de sangue que se aproxima à noite de quem está dormindo e provoca-lhes morte lenta aspirando sua substância vital".

Qualquer que seja sua origem, o vampiro é um ser que tinha vida, morreu fisicamente e então se ergueu do caixão para andar na terra e assustar os vivos. De acordo com McNally e Florescu (1995, p.124) a ideia do vampiro supõe o conceito oriental do eterno retorno, segundo o qual ninguém é realmente destruído, mas volta infinitas vezes em reencarnações. Eles são seres noturnos, e o brilho do sol transforma-os em pedra e algumas vezes em pó. Tipicamente, eles são descritos como vestindo capas pretas, são magros e pálidos e como tendo habilidade de voar e transformar-se em animais, sendo o morcego o mais famoso, embora se essas características estavam ou não presentes nos mitos originais sobre vampiros, não se sabe ao certo. Eles habitam o caixão durante o dia e perambulam à noite, não suportam igrejas e temem o alho. O propósito de suas andanças é buscar aquilo que mantém seu estado de morto-vivo: sangue. Esse é o alimento do vampiro, o fluido essencial e único para a sua "vida," e que nutre sua imortalidade. Suas vítimas ficam anêmicas e extremamente fracas até que comumente morrem, enquanto que ele, o vampiro, continua no estado de Nosferatu. O vampiro retira as qualidades de vida e saúde do sangue dos humanos ou animais tornando-se, assim, extremamente forte. 
É somente durante o dia que aqueles que procuram destruir este ser das sombras podem fazer suas tentativas, pois o poder do vampiro existe somente durante a noite, desaparecendo ao amanhecer já nas primeiras cantigas dos galos. Quando o corpo de um vampiro é exumado, sua aparência é de um corpo ainda em vida, apenas com algumas mudanças resultantes do tempo passado desde o seu enterro. O corpo parece ter engordado e inchado, os cabelos e as unhas crescidas, os lábios com manchas de sangue, olhos abertos, e as bochechas parecem até mais rosadas quando em vida. Para acabar com este morto vivo uma estaca deve ser cravada em seu coração. Então, a cabeça deve ser cortada e colocada entre as pernas. Uma vez que o vampiro é "morto", o corpo se transforma em pó imediatamente, ou no estado de decomposição que deveria estar naturalmente por ocasião do período subsequente a sua primeira morte. Frequentemente o corpo é também cremado para não deixar dúvidas da sua destruição total.

Somente um vampiro pode criar outro vampiro, então a lógica nos leva a crer que a história dos vampiros começou com um simples vampiro que criou outros vampiros. Como o fato de quem nasceu primeiro: o ovo ou a galinha, resta saber como nasceu o primeiro vampiro, pois, se não existiu nenhum vampiro para fazer o primeiro vampiro, como o primeiro vampiro nasceu? Dunn-Mascetti na introdução da obra Vampiros: além da saga Crepúsculo (2010, negrito nosso) relata que:

As origens dessas criaturas poderiam remontar ao antigo Egito, quando o culto e a veneração aos mortos eram representados de forma ritual em cerimônias nas quais os acólitos adoravam uma divindade semelhante a um pássaro preto. Esse pássaro sinistro representava o vôo da alma no momento da morte e sua viagem ao mundo das sombras. Os mortos que estavam "vivos" no mundo a que pertenciam, ocasionalmente voltavam e às vezes levavam os habitantes do mundo da luz para o desconhecido, roubando-lhes a vida.

Enquanto Vlad Tepes, um príncipe do século XV conhecido como O Empalador, parece ter inspirado o vampiro ficcional moderno, as raízes do vampiro "real" têm origens muito diferentes. Como uma entidade cultural, ele é um fenômeno mundial. Praticamente cada cultura 
tem sua história sobre vampiros. Os relatos seguem um padrão consistente: alguma desgraça inexplicável se abateria sobre uma pessoa, uma família ou uma cidade, talvez uma seca destruísse toda a plantação ou surgisse uma epidemia. Antes que a ciência fosse capaz de explicar os fenômenos meteorológicos e o surgimento de doenças e epidemias, os acontecimentos que não tinham uma explicação ou causas óbvias poderiam ser culpa do vampiro. Ele era uma resposta fácil para a velha questão do porque que coisas ruins acontecem às pessoas.

Duas doenças não explicadas pela ciência na época do surgimento do vampirismo podem contribuir para nos ajudar a entender a origem desta crença.

Uma teoria envolve uma doença rara conhecida por Porfiria. Basicamente, porfiria faz parte de um grupo de distúrbios raros transmitidos hereditariamente, conhecidos como "porfirinas" em que uma importante parte da hemoglobina, a heme, não é produzida corretamente podendo causar: palidez extrema, lábios muito vermelhos, pele sensível ao sol, aumento da produção de pêlos, saliva e urina vermelhas, dentes deformados, mau hálito, lábios contraídos com lábios caninos expostos, crises oriundas da ingestão de alho, bebidas alcoólicas, etc. ${ }^{3}$

A catalepsia pode ser uma outra doença que o vampirismo tenha se inspirado. A catalepsia é associada com a epilepsia e a esquizofrenia, distúrbios que afetam o sistema nervoso central. Uma pessoa que sofre de um ataque cataléptico pode ter ser corpo paralisado, a frequência cardíaca e a respiração praticamente inexistem. É possível que uma pessoa que esteja em uma situação de catalepsia seja dada como morta, especialmente porque o episódio da doença pode durar horas ou até mesmo dias ${ }^{4}$. Assim, no passado, as pessoas com essa doença poderiam ter sido confundidas como cadáveres e serem enterradas ainda com vida. Após, eles poderiam emigrar do estado da doença e então sair dos túmulos. Esse comportamento, sem explicação científica na época, foi associado com vampirismo.

Temos também algumas crenças que explicam as causas de alguém se transformar em vampiro após a morte. Entre as diversas crenças existentes, lembramos algumas. A principal causa se refere a alguma irregularidade

3 Fonte: http://educar.sc.usp.br/licenciatura/98/vampiros.html

4 Fonte: http://super.abril.com.br/superarquivo/2002/conteudo_120294.shtml 
que acontece nos rituais do enterro. Assim, a alma não recebe a permissão de descansar e é obrigada a caminhar no mundo dos vivos até que seu corpo tenha um enterro apropriado ou dentro das leis da igreja por terem sido excomungados ou que tenham morrido sem serem absolvidos de seus pecados em vida, e ainda, os que tenham cometido suicídio ou morrido por afogamento. Para aqueles que tiveram mortes violentas é negado um enterro apropriado, bem como, a aqueles que morreram por ação de um raio porque suas mortes são atribuídas diretamente à ira de Deus. Aqueles que foram perversos em vida eram enterrados em solos não consagrados por serem suspeitos de feitiçaria. Os que morreram sob a maldição de uma bruxa, as crianças recém-nascidas filhos ilegítimos de segunda geração, as crianças não batizadas, o sétimo filho de uma família, qualquer um que tenha sido tocado pelo sangue de um vampiro, ou qualquer um que é morto por um vampiro vai se tornar um vampiro após seu enterro.

Existem também dois mitos parecidos que explicam a origem do vampiro. Eles provavelmente são variações de contos do mesmo folclore. O primeiro mito é a história de Lamia, uma linda rainha que era amada por Zeus. Segundo Suenaga (2010) as lâmias (do grego laimos: garganta) da Grécia antiga, eram espécies de monstros ou demônios que apareciam sob a forma feminina com cabeça de mulher, corpo de dragão e voz de serpente, devoravam cadáveres em cemitérios e sugavam o sangue de criancinhas. Uma criança nasceu da união de Lamia e Zeus. Hera, sob o domínio da inveja e da ira, raptou a criança. Triste, Lamia foi viver nas profundezas do mar. O tempo passou, e Lamia, agora representada por uma forma raivosa, perambulou pelas noites, roubando e comendo os bebês recém-nascidos. Gradualmente ela passou a seduzir homens jovens, e enquanto mantinha relação sexual com eles, sugava o sangue deles até a morte. Lamia era capaz de mudar de uma forma bela até uma assustadora. A metade dragão era considerada um dos estágios de sua existência e/ou a transição entre uma linda mulher e uma serpentedragão. As vampiras femininas da modernidade são descritas como tendo o cabelo ruivo, pele pálida, olhos verdes.

O segundo mito envolve Lilith, provavelmente a primeira mulher de Adão. Lilith foi criada ao mesmo tempo em que Adão. Aguiar (2009, p. 63) nos diz que o legendário em torno da Bíblia fixou que Lilith seria uma primeira mulher de Adão, supostamente a mãe dos demônios ou 
dos falsos espíritos, uma espécie de Vampira, devoradora de crianças e adolescentes, chupadora de sangue e uma das mulheres mais marcantes da literatura. Ela recusou a ser submissa a Adão, criando assas e fugindo dele. Os anjos encontraram o esconderijo de Lilith e falaram que a punição dela por ter deixado Adão seria que todas as crianças que nascessem dela morreriam. Com tristeza profunda, ela pensou em suicídio. Os anjos, com pena, deram a ela completo poder sobre os bebês na primeira semana de vida. Mais tarde Lilith se tornou esposa de Satanás, ele mesmo descrito como uma serpente. Lilith também seduzia homens jovens e depois os matava.

Um importante fator que também contribuiu para a construção da figura do vampiro se refere ao grande medo primitivo da morte e tudo o que era conectado a ela. As crenças sobre o estado da morte variavam muito, e também aquelas relacionadas com a exata extensão da ligação entre a vida e a morte ${ }^{5}$. Os primitivos Europeus acreditavam que o corpo de um morto tinha que ser enterrado. Para que a alma passasse para qualquer tipo de mundo astral depois da morte, o enterro era uma necessidade. O corpo carregava o espírito da terra, então o espírito não seria libertado até que o corpo não fosse coberto por terra até sua total desintegração. Uma crença universal Eslávica acreditava que após a morte a alma pairava sobre a terra, flutuando perto do túmulo e visitando os lugares conhecidos em vida. Após quarenta dias a alma tentava reentrar no corpo enterrado e parcialmente decomposto pelo tempo. A alma é repelida pela decomposição, e deixa a terra para voltar para seu novo ambiente astral. Então o dever do homem era enterrar os corpos mortos para o descanso da alma e para salvar suas próprias vidas, pois caso contrário, as almas dos corpos que não foram enterrados assombrariam os vivos.

Os povos primitivos não viam a morte como a completa extinção da vida, ou a separação total dela. Eles acreditavam que o morto vivia em um mundo subterrâneo. No início pensava-se que esse mundo subterrâneo era a réplica exata do mundo dos vivos, crença reforçada pelo fato de que o sol parecia penetrar na terra quando anoitecia. Posteriormente, surgiu a concepção de que o mundo subterrâneo era escuro e horrível. Parecia ser a extensão do mundo subterrâneo que Ishtar [um dos deuses

5 Para aprofundamento do assunto recomendo a leitura da revista História Viva, Entre o

Céu e o Inferno, edição especial temática no. 25, 2009. 
da religião mesopotâmica: deusa da chuva, da primavera e da fertilidade] entrou na procura de seu amor, Tammuz. Como esse é um mito antigo, as ideias dos Gregos e dos Romanos sobre o inferno podem ter sido desenvolvidas da ideia que a Mesopotâmia tinha sobre o inferno. Para os antigos romanos, a alma descansa com o corpo dentro do túmulo. De acordo com Lecouteux (2005, p. 59) objetos relativos à manutenção da vida eram colocados em volta do túmulo para sustentar a alma em sua vida após a morte. A existência da alma depois da morte era muito enfatizada. Os Gregos também acreditavam na imortalidade da alma. Para eles, a alma residia com o corpo no túmulo.

Outro fator que se tornou parte do surgimento do vampiro diz respeito ao significado especial do sangue para a vida. As andanças noturnas dos vampiros eram especialmente para a procura de sangue. A obtenção dessa meta significava a renovação das capacidades corporais da vida humana, mas não somente temporariamente. Se alimentando do sangue dos vivos, o vampiro adquiria poder da palavra, força, resistência, potência sexual, e aparência de um corpo extremamente saudável. A vida do vampiro, de fato, vinha do sangue de suas vítimas, literalmente e figurativamente. A ideia de beber sangue para ser imortal não é estranha à mente humana. Indianos, gregos e cristãos fazem parte dessa concepção. O homem primitivo sentia que o sangue era a vida da pessoa. A prova empírica era o fato de que a perda de sangue em grande quantidade era sempre seguida de morte. Assim, a possessão do sangue era a essência da vida. Fisicamente levando sangue de uma pessoa para outra resultava na melhoria da vitalidade da sua própria vida. Desde que o sangue era tão precioso para a vida, se pensava que ele tinha uma alma própria, assim, beber do sangue de outra pessoa era identificado como a remoção e a possessão da alma e, ainda, a concepção de que por o corpo de alguém no seu próprio corpo significava obter mais vida.

Como exemplo podemos citar a Condessa húngara Elizabeth Bathory [1560-1614], conhecida também como A Condessa de Sangue, era acreditada como sendo uma vampira. Ela acreditava que banhar-se em sangue e/ou talvez beber sangue, era o segredo de manter-se jovem e bela para sempre. Por causa dessa crença, ela torturou e matou centenas de jovens, a maioria mulheres jovens. Ela foi condenada por seus crimes, sendo presa em um pequeno cômodo em um castelo onde morreu. Até onde vai a lenda e onde terminal o real nunca saberemos... 
A origem dos mitos eslavos sobre vampiros desenvolveram-se durante o século IX advindo de conflitos entre os pagãos e os cristãos. Os cristãos venceram os conflitos, mas algumas crenças pagãs, como a do vampiro, sobreviveram no folclore. A Romênia encontra-se geograficamente cercada por países Eslavos, então não é de admirar que seus vampiros sejam variantes dos vampiros Eslavos. Eles são chamados Strigoi, palavra baseada no termo Romano Strix aquele que pia como uma coruja, mas que após foi expandida para a significação de demônio ou bruxa e ainda ao espírito maligno que atacava as crianças durante a noite. Os romenos também usavam o termo vircolac - variação do grego vrykolakas - para descrever uma velha criatura mitológica parecida com um lobo que devorava o sol e a lua.

O termo vircolac descrevia uma pessoa que periodicamente se transformava em diversos animais, geralmente num porco, cachorro ou lobo. Nosferatu é um termo arcaico do antigo eslavo derivado aparentemente de nosofuratu, do grego nosophoros, "portador de pragas". Tem sido usado como uma palavra romena significando "Morto-vivo" ou "Demônio". A palavra se popularizou com a contribuição de Friedrich Wilhelm Murnau no filme Nosferatu (1938) baseado na obra Drácula (1897) de Bram Stoker 6 .

Na Romênia, acreditava-se, o vampiro aparecia primeiro e principalmente como um produto de nascimento irregular. As crianças nascidas fora do casamento ou que morressem antes de serem batizadas poderiam se tornar vampiros. Mulheres grávidas que não comessem sal ou que se permitissem ser vistas por um vampiro poderiam gerar uma criança vampira. O sétimo filho do mesmo sexo numa família tenderia a nascer com um rabo e se tornar um vampiro. Embora as crianças frutos de nascimentos irregulares fossem as principais candidatas ao vampirismo, qualquer pessoa poderia se tornar um vampiro se mordida por um deles. Outros vampiros em potencial incluíam pessoas que levavam uma vida pregressa (incluindo as que juravam em falso), bruxas (que tivessem tido relações com o Demônio), um cadáver sobre o qual um gato tivesse pulado ou uma pessoa que cometesse suicídio.

6 Fonte: http://www.consuladoromenia.com.br/turismo.php 
De acordo com Torrigo (2009, p. 16) os vampiros tem um lugar de destaque na religiosidade cigana. Segundo o pesquisador, entre os ciganos havia a profissão de "caçador de Vampiros" (Dhampir) sendo o caçador ele próprio filho de um Vampiro e "que morava entre os ciganos e os eslavos do sul” (MELTON, 2003, P. 87). O Mulo (aquele que está morto) era a forma mais conhecida de Vampiro cigano. Um morto-vivo que atacava durante a noite e voltava para a sepultura ao amanhecer. Este vampiro foi acreditado por voltar do túmulo e fazer coisas maldosas e também chupar o sangue de uma pessoa, geralmente um parente que tinha contribuído para com sua morte ou que não tivesse observado as cerimônias de enterro e até quem tivesse guardado as posses materiais do morto ao invés de destruí-las como era costume. Mesmo hoje em dia os Ciganos são frequentemente lembrados em filmes e na literatura de ficção sobre vampiros, sem dúvida, tendo a influência da obra Drácula de Bram Stoker na qual os ciganos aparecem carregando caixões do vampiro com terra nativa e ainda protegendo-o.

O tipo mais moderno dessa criatura apareceu por volta do século XII na Europa Oriental, mas o frenesi apareceu em algum momento do século XVIII. Nesta época houve um grande surto de vampiros na Europa Oriental que chamou a atenção do público. O que seu viu foi uma grande busca e caça para a exterminação dos vampiros pela população e até por funcionários do governo. Os corpos das pessoas que eram suspeitas de serem vampiros eram desenterrados e decapitados ou uma estaca era fincada no coração. Também era costume enterrar a pessoa de cabeça para baixo para que, ao tentar escapar, cada vez mais ela mergulhasse para as profundezas do solo.

Estudiosos começaram a analisar seriamente a existência dos vampiros pela primeira vez devido ao que foi considerado um surto de ataques de vampiros na Prússia Oriental em 1721 e no império HúngaroAustríaco de 1725 a 1734. Dois casos famosos chamaram a atenção: Peter Plogojowitz e Arnold Paole. 


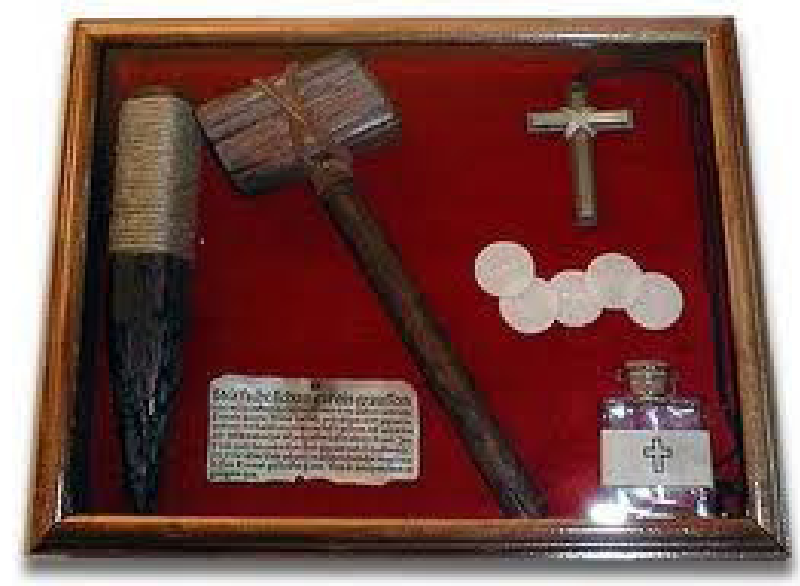

Conta a história que Peter Plogojowitz morreu aos 62 anos, mas retornou algumas vezes após a morte para pedir comida a seu filho. Quando o filho recusou, foi encontrado morto no dia seguinte. Logo Peter Plogojowitz retornou novamente e atacou a vizinhança que morreu através da perda de sangue. Arnold Paole, um ex-soldado da Sérvia que se tornou fazendeiro e foi atacado por um vampiro anos antes de morrer. Após a sua morte, pessoas começaram a morrer inexplicavelmente e então se acreditava que Paole tinha retornado para caçar os seus vizinhos. Segundo Dunn-Mascetti (2010, p. 22) o caso de Paul foi tão grave que atraiu a atenção das autoridades e estas solicitaram um relato da história que acabou sendo conhecida como Visium Et Repertum (Visto e Descoberto) e que de acordo com Bourre (1986, p. 6), o inquérito foi conduzido pelo tenente Buttner, do regimento de Alexandre de Vurtemberga, a 7 de Janeiro de 1732, que intrigou Luís XV e o Duque de Richelieu.

Estes dois casos foram documentados em detalhes. Oficiais do Governo examinaram os casos e os corpos, escreveram relatórios, e mais tarde livros foram escritos e distribuídos pela Europa após o caso de Paole. De acordo com Melton (2003, p. X) provavelmente a palavra vampire ou vampyre entrou pela primeira vez na língua inglesa quando a história foi publicada por dois periódicos ingleses, o London Journal e o Gentleman's Magazine em 1732. A história estimulou debates nos círculos intelectuais principalmente na tentativa de descobrir maneiras racionais de explicar o fenômeno desses relatos sobre vampiros. As controvérsias 
sobre se os casos realmente aconteceram ou não perduraram por muitas gerações. O problema foi evidenciado pela população rural que dizia estar sendo alvo de ataques de vampiros. Muitos estudiosos falaram que vampiros não existiam e atribuíram os casos a enterros prematuros, ou a raiva cujo um dos sintomas é uma sede excessiva.

O vampirismo, como descrito acima, tem, provavelmente, sua origem como sendo um produto dos medos, dos desejos, dos anseios e das crenças dos homens. O medo primitivo da morte, a busca por imortalidade, o desejo de controlar o meio ambiente, conceitos antropomórficos sobre a fertilidade da terra e a sua criação, seu animismo, sua concepção de universo e seu lugar nele, a gradual maturidade intelectual, convergiram para desenhar a imagem do vampiro que temos hoje. E como nos diz Lecouteux:

A espantosa unanimidade das reflexões, para além de todas as variantes, prova que o problema da vida e da morte é realmente fundamental, o que não é nada espantoso já que, em função das respostas apresentadas, o homem pode conhecer o desespero ou a esperança, encontrar um sentido para a sua existência ou conhecer o absurdo. (LECOUTEUX, 2005, p. 39).

O vampiro existe ou não? Ele certamente não pode ser estudado apenas como um fenômeno mitológico. Há explicações científicas, sociais e psicológicas ao invés de apenas concepções mitológicas. O folclore sobre os "hábitos" macabros dos vampiros pode ter advindo de fenômenos psicológicos ligados a ações de pessoas vivas em relação aos mortos. As perversões incluem: necrofilia, comer o morto, necrosadismo, sentir satisfação erótica através da mutilação de um cadáver e ainda o desejo não natural por sangue. Devido ao pouco desenvolvimento da ciência médica na época em que os vampiros eram temidos, as pessoas em coma ou em estado de choque eram na maioria das vezes, enterrados vivos, e aqueles que conseguiam escapar das sepulturas eram temidos por eles terem "retornados".

O desenvolvimento das concepções do homem sobre a criação ao longo das épocas tem cristalizado a forma como o vampiro pode ser descrito pela frase revolucionária: "Ontogenia recapitula filogenia" - o 
desenvolvimento individual da pessoa repete a história da raça. O desenvolvimento perceptivo de uma criança da infância até a idade adulta segue a mesma progressão que as concepções do homem sobre o seu ambiente, das raízes mais primitivas até a sua presente sofisticação. O homem primitivo via o seu mundo como um bebê vê o seu: um ambiente que ele não pode controlar: as estações, o dia e a noite, e a progressão da vida para a morte. Como uma criança faz, ele nomeou as coisas, pois dar nomes significa ter o controle e o poder. Ele atribuiu vida a objetos inanimados e tentou sobreviver nesse seu desconhecido universo.

Maravilhas diárias, como o nascer do sol a cada manhã, deram confiança ao homem do seu ambiente. Como uma criança que sente medo quando algo estranho acontece, também o homem sentia medo quando acontecia alguma mudança no ambiente em que vivia. Embora o homem tenha desenvolvido intelectualmente, ele sempre foi objeto de fantasias sombrias que, apesar do avanço tecnológico, nunca puderam ser explicadas. $\mathrm{O}$ vampiro nasceu dessas fantasias e ainda permanece na raça humana, como um medo infantil inexplicável pode permanecer em um homem para o resto de sua vida. E embora os vampiros "originais" há tempos já não existem, seu legado continua e eles continuam fascinando o mundo. Parece que nem a ciência e nem tampouco estacas de madeira conseguirão "matar" o vampiro para sempre.

A literatura, o cinema, o teatro e as artes em geral nos dão uma visão da sede do público por vampiros que parece ser infinita, assim como a sede dos vampiros por sangue. Escritores modernos de ficção, incluindo Stephanie Meyer, Anne Rice, Stephen King, André Vianco, e inúmeros outros, têm um folclore riquíssimo em que se basear.

\section{Bibliografia}

AGUIAR, Flávio. Sob o olhar da crítica literária. A Bíblia muito além da Fé. Entre Livros, ano I, n. 2, edição especial, p. 60-67, 2009.

ARGEL, Martha. NETO, Humberto Moura. (Org.). O vampiro antes de Drácula. São Paulo: Aleph, 2008.

BOURRE, Jean-Paul. Os Vampiros. Portugal: Euro - América, 1986. 
DUNN-MASCETTI, Manuela. Vampiros: além da saga Crepúsculo.

Tradução de Denise de C. Rocha Delela. São Paulo: Pensamento, 2010.

JÚNIOR, Pedro Augusto Moraes Simões. O Eterno Retorno de

Nosferatu. 2009. Disponível em http://migre.me/7tzgG. Acesso em setembro de 2010

LECOUTEUX, Claude. História dos Vampiros: autópsia de um mito. UNESP, 2005.

MCNALLY T, Raymond. FLORESCU, Radu. Em busca de Drácula e outros Vampiros. Tradução: Luiz Carlos Lisboa. São Paulo: Mercuryo, 1995.

MELTON, J. Gordon. O Livro dos Vampiros. São Paulo: M. Books do Brasil Editora LTDA, 2003.

MORAES, A.C. Marco. O Vampiro: Um retrato em mosaico. In:

FERREIRA, Cid Vale (org.). Voivode: Estudos Sobre os Vampiros. Jundiaí, São Paulo: Pandemonium, 2002.

STOKER, Bram. Drácula. Tradução de Theobaldo de Souza. Porto Alegre: LPM, 2007.

SUENAGA, Claudio Tsuyoshi. Vampiros: do gótico ao ufológico. Revista Sexto Sentido, São Paulo, n. 50, jun. 2010.

TORRIGO, Marcos. Vampiros: origens, lendas e mistérios. São Paulo: Idéia e Ação, 2009.

\section{Imagem:}

1) Disponível em http://3.bp.blogspot.com/-RLtXYVtKnTM/

Te5c2Zrf6CI/AAAAAAAAAEc/CEuvjPWR_DE/s1600/vampiro1.jpg. Consultado em 07/10/2012.

Disponível em http://3.bp.blogspot.com/_iBYMT_507zs/SQmxPcQS2-I/ AAAAAAAAfro/tTtIVvLOEL0/s400/Vampiro-1.jpg. Consultado em 07/10/2012. 
